\title{
Pencapaian Pelajar dalam Mata Pelajaran Geografi Sekolah Menengah di Sabah - Analisis Awal
}

\author{
Hanifah Mahat*, Paulin Chang Poh Ling, Nasir Nayan, Mohmadisa Hashim, Yazid Saleh \\ Jabatan Geografi dan Alam Sekitar, Fakulti Sains Kemanusiaan, Universiti Pendidikan Sultan Idris, 35900 Tanjong Malim, Perak
}

*Corresponding author: hanifah.mahat@fsk.upsi.edu.my

\begin{abstract}
This study intends to examine student achievement in subject of geography. This studyinvolves variables of attitudes, interest, teacher's role and parents' role with student achievement. This is a preliminary study involved only one district in Sabah, Kota Marudu district. Data were collected through a questionnaire which contains 40 items to measure, attitude, interest, teacher's role and parents' roles. Meanwhile, final examination results year 2015 used to measure student achievement for geography subject. A total of 257 Form Five students representing six schools that took geography involved in this study were selected through random sampling. Data were analysed using SPSS software by selecting the Pearson correlation analysis. Research finding showed that students' attitude has a significant relationship with student achievement. Meanwhile, interest, teacher's roles and parents' roles have no relationship with student achievement. The findings gave implications for the abolition of geography subjects if student achievement still remained in low-level. Hence, teachers and parents play an important role to form a high interest and a more positive attitude towards students in order to improve their achievement in subject of geography.
\end{abstract}

Keyword: Attitude, interest, role of teacher, parents' role, achievement

\begin{abstract}
Abstrak
Kajian ini bertujuan meneliti pencapaian pelajar dalam mata pelajaran geografi. Penelitian ini melibatkan pemboleh ubah sikap, minat, peranan guru dan peranan ibu bapa dengan pencapaian pelajar. Kajian ini merupakan kajian tinjauan awal kerana melibatkan satu daerah di Sabah iaitu daerah Kota Marudu. Data dikumpul melalui borang soal selidik yang mengandungi 40 item untuk mengukur sikap, minat, peranan guru dan peranan ibu bapa pelajar. Manakala, keputusan peperiksaan akhir tahun persekolahan 2015 digunakan sebagai sandaran pencapaian pelajar bagi mata pelajaran geografi. Seramai 257 orang pelajar tingkatan lima yang mewakili enam buah sekolah yang mengambil geografi terlibat dalam kajian ini yang dipilih secara persampelan rawak mudah. Data yang dikumpul dianalisis menggunakan perisian SPSS dengan memilih analisis korelasi Pearson. Dapatan kajian menunjukkan sikap mempunyai hubungan yang signifikan dengan pencapaian. Manakala minat, peranan guru dan peranan ibu bapa tidak mempunyai hubungan yang signifikan dengan pencapaian pelajar. Dapatan kajian ini memberi implikasi kepada pelaksanaan mata pelajaran geografi di sekolah jangka masa panjang. Pihak sekolah boleh membuat keputusan untuk tidak menawarkan subjek ini jika pencapaian pelajar masih kekal pada tahap yang rendah. Justeru, guru dan ibu bapa memainkan peranan yang penting dalam membentuk minat yang tinggi serta sikap yang lebih positif dalam kalangan pelajar agar dapat meningkatkan pencapaian mata pelajaran geografi.
\end{abstract}

Kata Kunci: Sikap, minat, peranan guru, peranan ibu bapa, pencapaian mata pelajaran geografi.

(C) 2017 Penerbit UTM Press. All rights reserved

\subsection{PENGENALAN}

Mata pelajaran geografi merupakan salah satu mata pelajaran yang ditawarkan dalam sistem pendidikan di Malaysia dan diperkenalkan di peringkat sekolah rendah semenjak tahun 1927 dan di peringkat universiti pada tahun 1959. Sebelum ini, mata pelajaran geografi ialah mata pelajaran teras bagi peringkat menengah rendah dan menegah atas. Namun, setelah pengenalan kepada Kurikulum Baru Sekolah Menengah (KBSM) pada tahun 1989, mata pelajaran geografi telah di pinda dari mata pelajaran teras kepada elektif (Kementerian Pendidikan Malaysia, 2015). "Penurunan" taraf mata pelajaran ini menyebabkan sesetengah sekolah tidak menawarkan mata pelajaran geografi kepada pelajar tingkatan empat dengan alasan tiada pelajar yang berminat untuk mengambilnya. Keadaan ini menyebabkan bilangan pelajar yang mempelajari geografi semakin berkurang. Pada masa yang sama terdapat juga pelajar yang mempunyai sikap yang beranggapan bahawa mata pelajaran ini adalah tidak penting (Abdul Hamid, Mohmadisa, Mohd. Faris \& Mohamad Suhaily Yusri,. 2006; Mohmadisa, Nasir, Mohamad Suhaily Yusri, \& Yazid, 2013). Malah salah satu sebab pihak sekolah tidak menawarkan mata pelajaran geografi di peringkat SPM juga disebabkan pencapaian cemerlang pelajar bagi mata pelajaran geografi adalah rendah dalam peperiksaan SPM (Shamsiah \& Azman, 2015; Soon Singh, Roslee, \& Dg. Norizah, 2013). Justeru wujud kebimbangan peminggiran terus mata pelajaran geografi sebagai mata pelajaran pilihan jika pelajar tidak menunjukkan pencapaian yang baik dalam peperiksaan. 
Keputusan peperiksaan menengah rendah bagi mata pelajaran geografi menunjukkan pencapaian yang lebih baik apabila Peperiksaan Menengah Rendah (PMR) digantikan dengan Pentaksiran Tingkatan 3 (PT3). Namun begitu, pada tahap peringkat menengah atas, pencapaian pelajar dalam mata pelajaran geografi adalah rendah disebabkan kebanyakan pelajar-pelajar yang mengambil mata pelajaran geografi merupakan pelajar yang mempunyai tahap pencapaian akademik yang rendah (Mohd Faris, Mohmadisa, \& Mohamad Suhaily Yusri, 2013). Malah laporan peperiksaan SPM tahun 2000 hingga 2009 yang dikeluarkan oleh Lembaga Peperiksaan Malaysia (LPM) menujukkan calon SPM mendapat markah yang rendah untuk komponen kemahiran geografi. Sementara itu, Shamsiah dan Azman (2015) menyatakan berdasarkan kupasan mutu jawapan peperiksaan SPM bagi mata pelajaran Geografi Kertas 2 tahun 2013, oleh LPM menunjukkan sebahagian besar calon gagal menjawab soalan dengan baik dan cemerlang.

Keadaan ini begitu ketara di beberapa Sekolah Menengah Kebangsaan dalam daerah Kota Marudu, Sabah. Berdasarkan data peperiksaan Pejabat Pendidikan Daerah Kota Marudu pada tahun 2016, didapati prestasi pelajar jelas kurang memuaskan dan semakin menurun. Sebagai contoh sejak empat tahun yang lepas iaitu pada tahun 2012 hingga 2015, didapati prestasi pelajar bagi mata pelajaran geografi di Sekolah Menengah Kebangsaan Bengkongan, Kota Marudu menunjukkan penurunan. Keadaan ini jelas menunjukkan peratus pelajar yang mendapat gred A hingga C sebanyak 31.95\% pada tahun 2012 menurun kepada $18.60 \%$ pada tahun 2015. Malah jumlah pelajar yang mengambil mata pelajaran geografi juga berkurang dari 97 orang pelajar pada tahun 2012 kepada 43 orang pelajar pada tahun 2015 bagi daerah Kota Marudu, Sabah. Justeru, satu bentuk kajian kes dijalankan di Sekolah Menengah Kebangsaan Daerah Kota Marudu, Sabah bertujuan untuk melihat faktor-faktor utama dan perhubungan antara sikap, minat, peranan guru dan ibu bapa yang mempengaruhi pencapaian pelajar dalam mata pelajaran Geografi.

\section{Sikap dan Minat Terhadap Pencapaian Geografi}

Sikap memainkan peranan yang penting untuk menentukan personaliti seseorang kerana ia dapat mempengaruhi cara memperlihatkan perbuatannya terhadap seseorang, objek dan peristiwa yang mereka alami (Aishah, Ruzaini \& Siti Asiyah, 2011). Nihra Haruzuan dan Chandrathevy (2010) menyatakan jika seseorang pelajar mempunyai sikap yang positif terhadap pembelajaran, maka pencapaian akademiknya yang diperoleh pasti baik. Hal ini disebabkan jika seseorang mempunyai sikap yang positif terhadap pelajaran tersebut, individu tersebut akan menyukai mata pelajaran tersebut.

Terdapat beberapa kajian yang dijalankan oleh para pengkaji yang menunjukkan bahawa sikap seseorang pelajar akan mempengaruhi pencapaian akademik dalam mata pelajaran geografi. Sebagai contoh dalam kajian Hibszer (2011) di sekolah menengah rendah yang terletak di Bandar Silesia Voivodeship Poland menunjukkan bahawa pelajar mempunyai sikap negatif terhadap pembelajaran mata pelajaran geografi. Melalui borang soal selidik yang diedarkan, pengkaji mendapati bahawa $94.6 \%$ daripada responden memberi jawapan bahawa belajar mata pelajaran geografi adalah susah. Kajian Ottati (2015); Hibzer (2011); Aydın (2011); Tomal (2010) mendapati bahawa antara sebab pelajar tidak menyukai mata pelajaran geografi adalah disebabkan terlalu banyak fakta dan konsep yang perlu ingat dan hafal. Tambahan itu, pelajar tidak suka mata pelajaran geografi kerana cara pengajaran guru yang membosankan dan hanya berpusatkan guru. Pendek kata, sikap pelajar terhadap mata pelajaran yang negatif ini boleh menyebabkan pencapaiannya merosot (Kaya, 2011).

Keadaan ini berlawanan sekiranya seseorang pelajar mempunyai sikap yang positif terhadap mata pelajaran geografi. Kajian Kaya (2011) merumuskan bahawa pelajar yang mempunyai sikap positif terhadap pembelajaran geografi boleh meningkatkan pencapaiannya. Misalnya dalam kajian Ozdemir (2012) mengenai sikap pelajar menengah atas terhadap mata pelajaran geografi di Karabuk, Turkey. Hasil kajian menunjukkan 83.5\% pelajar daripada 200 orang responden menyukai mata pelajaran geografi kerana mempunyai sikap positif terhadap mata pelajaran geografi. Kajian ini juga selari dengan dapatan kajian Tomal (2010) yang menunjukkan bahawa pelajar mempunyai sikap positif terhadap mata pelajaran geografi kerana pelajar berpendapat bahawa melalui pembelajaran geografi, mereka dapat mempelajari kawasan persekitaran dan tempat tinggal serta dapat menyelesaikan masalah yang dihadapi dalam kehidupan seharian.

Daripada penerangan di atas, jelaslah bahawa sikap yang ada pada pelajar terhadap mata pelajaran geografi sangat penting kerana ia boleh mempengaruhi pencapaian seorang pelajar. Pelajar yang tidak mempunyai sikap positif terhadap sesuatu mata pelajaran mempunyai masalah untuk mencapai kejayaan dalam mata pelajaran tersebut. Oleh itu, bagi mencapai kejayaan dalam pembelajaran geografi, pembangunan sikap pelajar yang positif terhadap mata pelajaran tersebut tidak harus diabaikan.

Minat yang ada pada seseorang sangat penting kerana ia boleh mempengaruhi sama ada pelajar tersebut ingin belajar atau tidak. Jika seseorang tidak mempunyai minat yang tinggi dalam sesuatu bidang, ia akan menjadi penghalang seseorang untuk memperoleh pencapaian yang cemerlang (Johari \& Norsuriani, 2011). Kajian Uly (2012) menekankan bahawa minat pelajar terhadap sesuatu pelajaran merupakan kekuatan yang akan mendorong pelajar untuk tekun belajar. Ini bermaksud minat yang ada dalam diri seseorang pelajar terhadap mata pelajaran geografi sangat penting kerana ia boleh mendorong seseorang berusaha lebih gigih dan giat ke arah mencapai keputusan yang cemerlang. Minat yang tinggi terhadap mata pelajaran geografi dapat meningkatkan pencapaian pelajar dan, sebaliknya minat yang kurang boleh menjejaskan pencapaiannya (Normah, 2012; Roslee \& Mohamad Saifullah, 2013). Terdapat beberapa kajian yang menunjukkan sebab pelajar kurang minat terhadap pembelajaran geografi. Antaranya kajian Nuratu (2014), yang mendedahkan bahawa pelajar kurang minat terhadap pembelajaran geografi disebabkan hasil kandungan pembelajaran geografi yang luas ditambah pula dengan kekurangan bahan pembelajaran dan prasarana seperti makmal geografi, perpustakaan, stesen kaji cuaca dan infrastruktur lain yang diperlukan untuk menjadi pembelajaran lebih bermakna.

Selain itu, pelajar juga menyatakan bahawa kekurangan guru yang berkelayakan untuk mengajar mata pelajaran ini dilihat sebagai sebab minat mereka semakin berkurangan (Nuratu, 2014). Sementara itu kajian Abdul Said, Baharom, Mohd Yusof, Mohamad Johdi dan Francis (2011) turut menegaskan iaitu pelajar kurang berminat disebabkan sikap guru yang tidak mempelbagaikan kaedah dalam pengajaran mata pelajaran geografi dan tidak terdapat interaksi yang baik antara guru dan pelajar (Rohani, Hazri \& Nordin, 2010). Kesimpulannya, minat seseorang pelajar terhadap sesuatu mata pelajaran geografi memainkan peranan yang sangat penting dalam proses pembelajaran untuk mendapat pencapaian yang lebih baik. Hal ini kerana apabila seseorang itu minat dan suka, secara langsung individu tersebut akan bertindak positif dalam pelbagai bidang yang diceburi. 


\section{Kajian Tentang Peranan Guru Geografi.}

Masyarakat sekeliling umumnya melabelkan guru sebagai role model kepada pelajar. Setiap perkara yang disampaikan atau pergerakan yang dilakukan oleh guru sering diperhatikan oleh pelajar. Guru juga boleh dikatakan seorang ibu bapa pelajar yang berada di kawasan sekolah. Hal ini kerana guru terlibat secara langsung untuk mendidik serta membimbing pelajar. Pernyataan ini disokong dalam kajian Mohamad Johdi, Mazliza, dan Jane (2012) yang menunjukkan 100\% pelajar menyokong pernyataan bahawa guru merupakan pembimbing utama. Justeru itu, cara bimbingan guru adalah penting untuk menghasilkan pelajar yang cemerlang. Dalam kajian Alimi dan Balogun (2010); Rilwani, Akahomen dan Gbakeji (2014) menunjukkan guru adalah signifikan dalam mempengaruhi prestasi pelajar dalam mata pelajaran geografi.

Peranan guru sebagai seorang pembimbing dilihat daripada pelbagai aspek sama ada dari segi tahap kualiti, sikap guru dan kaedah pengajaran yang dilakukan dalam kelas. Menurut Rohani et al. (2010) guru yang berkualiti dapat meningkatkan komitmen pelajar dalam aktiviti pembelajaran serta penglibatan intelektual pelajar dalam proses pengajaran dan pembelajaran (PdP) di dalam bilik darjah. Selain itu, guru berkualiti turut meningkatkan minat pelajar serta membentuk sikap pelajar yang positif dalam pembelajaran. Malah Mutua (2012) juga sependapat dengan pernyataan tersebut di mana beliau menyatakan guru geografi yang berkualiti merupakan guru yang kreatif dalam memilih strategi pembelajaran yang sesuai boleh menyebabkan sistem penyampaian menjadi lebih efektif, menarik dan dapat merangsang minat pelajar untuk belajar. Sebaliknya kualiti guru geografi yang rendah menunjukkan cara pengajaran guru dalam kelas yang lemah seperti tidak menggunakan alat bantu mengajar. Keadaan ini seterusnya mempengaruhi minat pelajar dalam pembelajaran geografi dan menyebabkan penurunan prestasi dalam mata pelajaran geografi. (Abdul Said et al, 2011; Rilwani et al, 2014).

Aplikasi ICT dalam PdP yang berkesan dapat mewujudkan pembelajaran yang menarik dan mencapai objektif PdP. Seterusnya dapat meningkatkan pencapaian pelajar dalam mata pelajaran geografi. Pernyataan ini turut dibuktikan dalam kajian Mastura (2014); Roslee dan Mohamad Saifullah (2013) di sekolah menengah, didapati penggunaan Google Earth dalam pembelajaran geografi dapat menarik minat pelajar dan dapat meningkatkan pencapaian pelajar. Pada masa yang sama dalam kajian Normah (2012) mengenai kesan penggunaan video dan buku teks terhadap pencapaian, minat dan motivasi pelajar dalam topik putaran dan peredaran bumi juga memperlihatkan penggunaan video dalam pengajaran dapat meningkatkan pencapaian pelajar berbanding buku teks. Selain itu, kajian Abdul Said et al. (2011) juga menunjukkan penggunaan alat bantu mengajar yang menarik seperti model bentuk muka bumi sungai dalam mata pelajaran geografi dapat meningkatkan kefahaman dan prestasi pelajar.

Pendekatan pembelajaran guru dalam sesuatu pelajaran juga berperanan mempengaruhi pemahaman pelajar seterusnya pencapaian pelajar. Sebagai contoh dalam kajian Aydın (2011) dan Ozdemir (2012), dapatan menunjukkan bahawa pendekatan pembelajaran berpusatkan pelajar memberi kesan positif terhadap pencapaian dan sikap pelajar terhadap pembelajaran geografi. Kajian Zahara dan Suzela (2011) mengenai kesan strategi pembelajaran terhadap pencapaian geografi tingkatan satu turut menunjukkan terdapat perubahan sikap pelajar ke arah yang positif terhadap mata pelajaran geografi dengan kaedah pembelajaran koperatif. Pada masa yang sama, pelajar turut menunjukkan minat yang dalam terhadap topik yang diajar. Keadaan ini menunjukkan kaedah pengajaran dan pembelajaran yang sistematik dapat memberi sumbangan yang signifikan ke arah peningkatan pencapaian dalam mata pelajaran geografi.

Kesimpulannya, guru memainkan peranan yang penting sama ada dari sikap guru itu sendiri, kualiti guru atau pun kaedah pengajaran yang digunakan dalam pengajaran dan pembelajaran geografi. Hal ini kerana sikap guru yang positif dapat melahirkan pelajar yang berfikiran positif. Tambahan pula, guru yang berkualiti mampu mewujudkan pembelajaran yang efektif dan efisien seterusnya dapat mempengaruhi pembelajaran dan pencapaian pelajar dalam mata pelajaran geografi. Akhir sekali, kaedah pengajaran yang menarik serta mengikuti perkembangan pendidikan pada abad-21 ini dapat menarik minat pelajar untuk belajar dan mengubah sikap negatif pelajar ke arah yang positif. Keadaan ini secara tidak langsung boleh meningkatkan pencapaian pelajar dalam pembelajaran geografi. Pengaruh guru terhadap minat, sikap dan pencapaian pelajar dalam kajian ini hanya diteliti berdasarkan kajian tinjauan terhadap pelajar sahaja dan kajian ini tidak meneliti amalan PdP dalam kalangan guru geografi.

\section{Kajian Peranan Ibu Bapa dalam Mempengaruhi Pendidikan Anak}

Ibu bapa memainkan peranan yang sangat penting untuk mewujudkan suasana pembelajaran yang sesuai serta memastikan proses pembelajaran anak mereka adalah betul. Hal ini kerana, keluarga merupakan persekitaran pertama anak-anak sejak dilahirkan dan pendidikan asas seorang anak adalah bermula di sesebuah keluarga. Antara peranan ibu bapa yang paling besar ialah melibatkan diri dalam pembelajaran kanak-kanak. Menurut Zulkifli, Jamilah, Aminah, dan Ismi (2011), penglibatan ibu bapa adalah dari segi perbincangan, penjagaan dan komunikasi yang boleh memberi kesan positif terhadap pencapaian akademik pelajar.

Penglibatan ibu bapa terhadap pencapaian anak sering mendapat perhatian pengkaji. Antaranya Farooq et al. (2011) di sebuah sekolah menengah bandar metropolitan Pakistan menyatakan bahawa penglibatan ibu bapa dalam pendidikan anak mereka boleh meningkatkan kadar kejayaan akademik anak-anak mereka. Pernyataan ini turut disokong dalam kajian Zulkifli et al. (2011) yang menunjukkan dapatan analisis korelasi Pearson mempunyai hubungan yang signifikan antara penglibatan ibu bapa dan pencapaian pelajar dan analisis regresi mendapati penglibatan ibu bapa memberi sumbangan $74.5 \%$ ke atas pencapaian akademik pelajar secara umum.

Penglibatan ibu bapa dari segi perbincangan yang melibatkan keputusan peperiksaan anak, perbincangan mengenai aktiviti sekolah dan perbincangan tentang maklumat yang telah dibaca oleh ibu bapa dengan anak (Zulkifli et al. 2011). Melalui perbincangan antara ibu bapa dan kanak-kanak, ibu bapa dapat memberi pendedahan awal pentingnya sesuatu mata pelajaran tersebut agar anak mereka dapat memupuk minat mereka sejak kecil. Pada masa yang sama, anak-anak mereka dapat mengaplikasikan perkara yang dipelajari dalam kehidupan seharian serta ibu bapa juga dapat mengetahui perkembangan pelajaran atau pencapaian anak mereka dalam sekolah. Selain itu, perbincangan ini juga dapat menghasilkan suatu pandangan bersama tentang sasaran anak dalam pelajaran seterusnya membantu mencapai cita-cita anak mereka (Abd. Razak \& Noraini, 2011).

Dari segi penjagaan di rumah pula, Zulkifli et al. (2011) menyatakan peranan ibu bapa ialah memastikan anak mereka menyiapkan kerja sekolah, menghadiri kelas tambahan dan memastikan anak mereka mempunyai jadual waktu belajar di rumah. Di samping itu, Azmy (2012) menyatakan bahawa penjagaan ibu bapa di rumah adalah seperti menemani anak semasa mereka sedang belajar kerana kehadiran ibu bapa dapat mengukuhkan perasaan dan mengekalkan tumpuannya. Keadaan ini boleh memberi semangat kepada anak mereka seterusnya mempunyai motivasi untuk belajar bersungguh-sungguh bagi memperoleh pencapaian yang cemerlang. 
Penglibatan ibu bapa dari segi komunikasi adalah seperti mengingatkan anak untuk tekun belajar, memberi galakan dan dorongan, serta menasihatkan anak mereka berusaha mendapatkan markah terbaik dalam peperiksaan (Zulkifli et al. 2011). Kajian Mohamad Johdi et al. (2012) mengenai faktor-faktor mempengaruhi penilaian menengah rendah di Sabah turut sokong pernyataan tersebut. Kajian mendapati ibu bapa merupakan faktor dominan mempengaruhi kecemerlangan pencapaian (PMR) pelajar. Hal ini kerana ibu bapa boleh mendorong pelajar berusaha lebih tinggi dan memupuk semangat yang lebih tinggi untuk belajar. Sebaliknya beliau juga menyatakan bahawa ibu bapa pelajar yang kurang prihatin terhadap pelajar akan mempengaruhi perkembangan pendidikan anak-anaknya.

Komunikasi antara anak dan ibu bapa amat penting. Kajian Abd. Razak dan Norani (2011) menegaskan bahawa komunikasi yang jelas antara ibu bapa dan anak didapati memberikan peluang untuk ibu bapa berinteraksi dengan baik untuk terlibat dalam pelajaran anak-anak. Sehubungan itu, dalam komunikasi ini, anak-anak mempunyai ruang untuk bermesra dan bertukar-tukar pandangan mengenai pengetahuan serta bertanyakan pendapat ibu bapa dalam pelajaran mereka. Pernyataan ini turut disokong dalam kajian Norhaida, Muhammad Firdaus, Nor Rosmawati, Farah, dan Haliyana (2015) di Kolej Universiti Islam Antarabangsa Selangor. Kajian menunjukkan faktor ibu bapa melalui komunikasi mempunyai hubungan yang paling signifikan ke atas prestasi akademik pelajar. Hal ini kerana, melalui komunikasi, perhubungan kekeluargaan dapat dieratkan. Kesan hubungan kekeluargaan yang rapat ini, menyebabkan anak-anak lebih berasa selesa untuk meluahkan permasalahan yang mereka hadapi, berkongsi pendapat atau pengalaman yang mereka lakukan. Justeru itu, ibu bapa boleh mengetahui masalah yang mereka hadapi dalam pembelajaran mereka seterusnya mencari langkah untuk mengatasi.

Sikap seorang ibu bapa terhadap anak mereka turut mempengaruhi pencapaian kanak-kanak. Menurut Mutua (2012), sikap ibu bapa yang positif akan membawa kepada penerimaan kanak-kanak yang akan berkembang menjadi anak yang bersemangat, bertanggungjawab dan penuh perhatian. Ciri-ciri ini yang tertanam dalam hidup seseorang anak mampu berjaya dalam peperiksaan. Tambahan itu, beliau menyatakan bahawa ibu bapa yang bersikap positif juga akan memberi dorongan dan mengambil berat perkembangan prestasi anak mereka di sekolah. Keadaan ini seterusnya boleh membawa kepada keputusan yang cemerlang.

Kesimpulannya, ibu bapa perlu memainkan peranan sepenuhnya sebagai penjaga, penasihat dan kaunselor atau perawat dari segi mental, rohani dan fizikal kanak-kanak agar dapat membantu memperkembangkan pembelajaran kanak-kanak yang positif seterusnya dapat menghasilkan pencapaian yang baik. Kajian ini meneliti peranan ibu bapa dari perspektif anak mereka dan tidak melibatkan kajian langsung terhadap ibu bapa.

\subsection{METODOLOGI}

Kajian ini merupakan kajian tinjauan yang berbentuk korelasi. Kaedah ini bersesuaian untuk melihat faktor-faktor yang mempengaruhi pencapaian mata pelajaran geografi. Kajian awal ini hanya melibatkan Sekolah Menengah Kebangsaan di daerah Kota Marudu, Sabah yang menawarkan mata pelajaran geografi untuk pelajar tingkatan 4 dan 5. Mengikut data Pejabat Pendidikan Daerah Kota Marudu, Sabah terdapat enam (6) buah Sekolah Menengah Kebangsaan di daerah Kota Marudu yang menawarkan mata pelajaran Geografi. Data yang diperoleh daripada setiap sekolah menunjukkan 760 orang pelajar tingkatan lima di seluruh daerah ini. Ini bermakna jumlah sampel kajian mengikut Krejcie dan Morgan (1970) adalah sebanyak 257 sampel. Malah bilangan sampel ini turut melebihi cadangan Cohen, Manion dan Morrison (2001) iaitu jika populasi antara 500 -1000 orang bilangan sampel sebanyak 217-278 pada aras signifikan .05. Dalam menentukan jenis persampelan, kajian memilih persempelan kelompok (cluster sampling) untuk enam kelompok sekolah dan seterusnya menggunakan persampelan rawak mudah untuk memilih sampel kajian. Sampel yang dipilih terdiri daripada pelbagai jantina, bangsa dan kumpulan pencapaian. Pecahan bilangan sampel bagi setiap sekolah adalah berbeza mengikut bilangan pelajar di sekolah tersebut ( Jadual $1)$.

Jadual 1 Pecahan sampel setiap sekolah

\begin{tabular}{llcc}
\hline Bil & Sekolah & Jumlah Pelajar (Orang) & Sampel Kajian \\
\hline 1 & SMK I & 218 & 74 \\
2 & SMK II & 109 & 37 \\
3 & SMK III & 93 & 32 \\
4 & SMK IV & 171 & 58 \\
5 & SMK V & 97 & 33 \\
6 & SMK VI & 72 & 24 \\
\hline & JUMLAH & 760 & 257 \\
\hline
\end{tabular}

Instrumen kajian yang digunakan dalam kajian ini adalah borang soal selidik. Pengumpulan data dilakukan dengan mengedarkan borang soal selidik kepada para pelajar yang mengambil mata pelajaran geografi di kawasan tersebut. Borang soal selidik yang diedarkan terdiri daripada tujuh bahagian iaitu (A) Latar belakang responden (B) Sikap pelajar terhadap mata pelajaran geografi (C) Minat pelajar terhadap mata pelajaran geografi (D) Peranan guru dalam pencapaian mata pelajaran geografi pelajar (E) Peranan ibu bapa dalam pencapaian mata pelajaran geografi pelajar dan (F) Pandangan dan cadangan responden. Item-item di bahagian B hingga Bahagian $\mathrm{E}$ adalah menggunakan skala Likert 5 point iaitu skala 1 mewakili 'Tidak bersetuju' 2= Kurang bersetuju; 3=Kurang pasti; $4=$ Bersetuju dan $5=$ Sangat bersetuju. Maklumat item setiap pemboleh ubah kajian di Jadual 2. Item-item yang diguna pakai untuk kajian turut disemak oleh pakar dalam bidang berkenaan untuk memastikan item dan bahasa yang digunakan adalah sesuai dan tepat. Malah hasil semakan nilai kebolehpercayaan (alpha cronbach), kesemua pemboleh ubah dalam kajian rintis melebihi 0.7. Menurut Pallant (2010), nilai Alpha Cronbach sebanyak 0.70 atau ke atas adalah nilai yang baik dan boleh diterima bagi skala instrumen yang mempunyai sepuluh atau lebih item. Begitu juga nilai alpha cronbach kajian sebenar juga melebihi 0.7 (Jadual 3). 
Jadual 2 Bilangan dan sumber item setiap pemboleh ubah

\begin{tabular}{llll}
\hline Bah. & Aspek yang diukur & Bil item & Sumber item \\
\hline A & $\begin{array}{l}\text { Latar belakang } \\
\text { B }\end{array}$ & $\begin{array}{l}1-9 \\
1-10\end{array}$ & $\begin{array}{l}\text { Dipetik dan diubah suai dari Hibszer (2011); Jerie dan Mahamod (2011); } \\
\text { Zulzana et al., (2012) dan Ozdemir (2012). }\end{array}$ \\
C & Minat & $1-10$ & $\begin{array}{l}\text { Dipetik dan diubah suai dari Hibszer (2011); .Zulzana et al., (2012) dan } \\
\text { Ozdemir (2012). }\end{array}$ \\
D & Peranan guru & $1-10$ & $\begin{array}{l}\text { Dipetik dan diubah suai dari Mohamad Johdi et al., (2012); . Abdul Said et } \\
\text { al., (2011);Roslee \& Mohamad Saifullah, (2013). }\end{array}$ \\
E & Peranan Ibu Bapa & $1-10$ & $\begin{array}{l}\text { Dipetik dan diubah suai dari Katz, Kaplan, \& Buzukashvily, (2011); . } \\
\text { Mohamad Johdi et al., (2012). }\end{array}$ \\
\hline
\end{tabular}

Jadual 3 Ringkasan analisis kebolehpercayaan instrumen

\begin{tabular}{llcc}
\hline Pemboleh ubah & Bil.Item & $\begin{array}{c}\text { Kajian Rintis } \\
\text { (Nilai alpha cronbach) }\end{array}$ & $\begin{array}{c}\text { Kajian sebenar } \\
\text { (Nilai alpha cronbach) }\end{array}$ \\
\hline Sikap Pelajar & 10 & .82 & .833 \\
Minat Pelajar & 10 & .723 & .838 \\
Peranan Guru & 10 & .797 & .738 \\
Peranan Ibu bapa & 10 & .716 & .831 \\
\hline
\end{tabular}

Dalam kajian ini, analisis yang digunakan dalam kajian ini ialah korelasi iaitu bertujuan menganalisis hubungan antara pemboleh ubah sikap, minat, peranan guru, dan peranan ibu bapa terhadap pencapaian pelajar geografi. Bagi melihat kekuatan hubungan, nilai $p$ akan dilihat sama ada nilai $\mathrm{p}$ kurang atau sama dengan $.05(\mathrm{p} \leq 0.05)$ atau lebih daripada $.05(\mathrm{p}>0.05)$. Nilai $(\mathrm{p} \leq 0.05)$, menunjukkan terdapat hubungan yang signifikan antara dua pemboleh ubah, manakala nilai $p(p>0.05)$ menunjukkan tidak wujud hubungan yang signifikan antara dua pemboleh ubah berkenaan. Bagi menentukan sama ada hubungan antara dua pemboleh ubah adalah kuat, sederhana atau lemah, satu pengelasan nilai pekali Pearson (Jadual 4) boleh dirujuk mengikut pengelasan hubungan korelasi Cohen (1998).

Jadual 4 Pengelasan kekuatan hubungan/korelasi

\begin{tabular}{cc}
\hline Nilai $\mathrm{r}(-1 \leq r \leq 1)$ & Interpretasi hubungan \\
\hline .10 hingga .29 & Lemah \\
.30 hingga .49 & Sederhana \\
.50 hingga 1.0 & Kuat \\
\hline Sumber: Cohen (1998).
\end{tabular}

\subsection{DAPATAN DAN PERBINCANGAN}

Bilangan keseluruhan responden yang disoal selidik dalam kajian ini adalah seramai 257 orang responden yang mewakili enam buah sekolah di daerah Kota Marudu yang menawarkan mata pelajaran geografi bagi pelajar tingkatan 5. Berdasarkan dapatan kajian yang diperoleh seramai 88 orang (34.2\%) adalah responden lelaki dan selebihnya 169 orang (65.8\%) responden perempuan. Responden tersebut terdiri daripada kaum yang berbeza iaitu majoriti responden adalah lain-lain kaum seperti Dusun, Rungus, Iban dan Bajau seramai 207 orang $(80.5 \%)$. Manakala hanya 37 orang $(14.4 \%)$ berkaum Melayu diikuti dengan 11 orang Cina (4.3\%) dan 2 orang India (8\%).

Kajian ini ingin meneliti hubungan pemboleh ubah sikap, minat, peranan guru dan peranan ibu bapa terhadap pencapaian pelajar dalam mata pelajaran geografi. Hasil analisis korelasi pearson (Jadual 5), bagi pemboleh ubah sikap dan pemboleh ubah pencapaian menunjukkan hubungan yang lemah tetapi signifikan $(r=-0.180, p>0.05)$. Hal ini bermakna, sikap seseorang pelajar berhubungan dengan pencapaiannya sama ada pelajar itu mempunyai sikap yang positif atau sikap yang negatif. Dapatan kajian menunjukkan ia selari dengan pendapat pengkaji seperti kajian Hibszer (2011); Kaya (2011) dan Ozdemir (2012) di mana mereka mendapati bahawa pelajar yang mempunyai sikap negatif terhadap mata pelajaran geografi boleh menyebabkan pencapaiannya rendah dan sebaliknya pelajar yang mempunyai sikap yang positif boleh mendapat pencapaian yang tinggi. Ringkasnya, sikap pelajar terhadap mata pelajaran geografi mahupun mata pelajaran lain adalah sangat penting kerana ia boleh mempengaruhi pencapaiannya secara tidak langsung melalui tindakannya. Lantaran itu, guru dan ibu perlu mewujudkan sikap negatif pelajar pada tahap yang minimum malah sikap positif yang tinggi terhadap mata pelajaran geografi dengan kaedah-kaedah yang dibincangkan sebelum ini. Seterusnya pemboleh ubah minat dan pencapaian pelajar pula, dapatan kajian menunjukkan hubungan yang lemah dan tidak signifikan $(r=-0.042, p>0.05)$. Dapatan ini tidak selari dengan dapatan kajian Normah (2012) yang menunjukkan bahawa terdapat hubungan yang signifikan antara minat dengan pencapaian pelajar. Dalam kajian ini, menunjukkan walaupun pelajar mempunyai minat terhadap mata pelajaran geografi tetapi minat tersebut tidak mempengaruhi dalam pencapaiannya. Keadaan ini jelas menunjukkan peranan guru dalam sesuatu pembelajaran dapat mempengaruhi minat pelajar dalam mata pelajaran geografi seterusnya pencapaian seorang pelajar terutamanya dari segi strategi pembelajaran dan alat bantu mengajar. Pernyataan tersebut turut di bukti dalam kajian Roslee dan Mohamad Siafullah (2013); Zahara dan Suzela (2011) yang menunjukkan penggunaan strategi pembelajaran koperatif dan penggunaan Google Earth dalam pembelajaran geografi dapat menarik minat pelajar dan dapat meningkatkan pencapaian pelajar. Oleh itu, guru digalakkan sentiasa membuat penambahbaikan kaedah pengajaran dan alat bantu mengajar yang digunakan bagi menarik minat pelajar memandangkan dunia kini berkembang semakin maju. 
Seterusnya bagi pemboleh ubah peranan guru dan peranan ibu bapa, wujudnya hubungan korelasi yang sederhana dan signifikan $(\mathrm{r}=$ $0.424, \mathrm{p}<0.05)$. Pada masa yang sama jika dilihat melalui dapatan pemboleh ubah peranan guru dan pemboleh ubah pencapaian pula menunjukkan hubungan korelasi yang lemah dan tidak signifikan $(\mathrm{r}=-0.51, \mathrm{p}>0.05)$. Begitu juga dengan pemboleh ubah peranan ibu bapa dan pemboleh ubah pencapaian, dapatan menunjukkan hubungan korelasi yang lemah dan tidak signifikan $(\mathrm{r}=-0.049$, $\mathrm{p}>0.05)$. Malah dalam kajian Aydn (2011); Rohani et al (2010); dan Ozdemir (2012) telah membincangkan bagaimana guru dapat membentuk sikap pelajar yang positif dan seterusnya dapat mempengaruhi sikap pelajar terhadap pembelajaran geografi sama ada dari segi pengajaran guru itu atau sikap guru itu sendiri. Akhir sekali jika diteliti pemboleh ubah peranan guru dan pemboleh ubah pencapaian menunjukkan hubungan korelasi yang lemah dan tidak signifikan $(\mathrm{r}=-0.51, \mathrm{p}>0.05)$. Begitu juga dengan pemboleh ubah peranan ibu bapa dan pemboleh ubah pencapaian, dapatan menunjukkan hubungan korelasi yang lemah dan tidak signifikan $(\mathrm{r}=-0.049$, $\mathrm{p}>0.05)$. Melalui dapatan tersebut, jelas menunjukkan guru dan ibu bapa mempunyai hubungan untuk mempengaruhi pencapaian pelajar dalam mata pelajaran geografi. Ini bermaksud sekiranya hanya ibu bapa sahaja yang terlibat dalam pembelajaran anak-anak, ibu bapa mereka tidak mempengaruhi pencapaian pelajaran anak mereka. Sebaliknya sekiranya hanya guru sahaja yang terlibat dalam pembelajaran pelajar, guru juga tidak mempengaruhi pencapaian pelajar sepenuhnya. Lanjutan daripada huraian yang telah dinyatakan, maka kedua-dua pihak perlu bekerjasama antara satu sama lain untuk membantu pembelajaran anak-anak agar mendapat pencapaian yang cemerlang. Kenyataan ini menunjukkan ianya selari dengan Teori Ekologi Bronfenbrenner (1979) dalam lapisan mesosistem yang menyatakan bahawa jaringan hubungan yang baik antara pihak guru dan ibu bapa mampu melahirkan pelajar-pelajar yang cemerlang dalam pelbagai aspek. Sementara itu. Norzahida (2013) juga menjelaskan bahawa penglibatan ibu bapa dalam aktiviti sekolah menerusi sumber kewangan atau sumbangan moral secara langsung dapat meningkatkan pencapaian akademik dan sahsiah pelajar. Berdasarkan kedua-dua pernyataan tersebut, jelas bahawa perlunya hubungan antara guru dan ibu bapa dalam mewujudkan pembelajaran kanak-kanak berkesan.

Jadual 5 Keputusan korelasi pemboleh ubah kajian

\begin{tabular}{lcc}
\hline Pemboleh ubah & \multicolumn{2}{c}{ Pencapaian } \\
& $\mathbf{r}$ & $\mathbf{p}$ \\
\hline Sikap & $-.180^{* *}$ & .004 \\
Minat & -.042 & .507 \\
Peranan guru & -.051 & .413 \\
Peranan ibu bapa & -.049 & .436 \\
\hline **. Correlation is significant at the 0.01 level (2-tailed). & &
\end{tabular}

\subsection{KESIMPULAN}

Secara keseluruhannya, kajian ini merumuskan bahawa pencapaian mata pelajaran geografi pelajar adalah berhubungan langsung dengan sikap. Namun pemboleh ubah minat, peranan guru dan peranan ibu bapa terhadap pencapaian harus diberi perhatian hasil kajian ini. Sehubungan itu, usaha memperbaiki dan meningkatkan pencapaian geografi dalam kalangan pelajar harus diambil perhatian oleh pihak guru dan pihak ibu bapa agar pelajar yang mengambil mata pelajaran geografi ini benar-benar lahir sebagai modal insan yang mencintai alam sekitar, mampu memelihara dan memulihara alam sekitar dan pada masa yang sama dapat diseimbangkan dengan pembangunan negara dalam bidang ekonomi, sains dan teknologi. Keempat-empat pemboleh ubah yang dinyatakan masing-masing memainkan peranan yang penting dalam mempengaruhi pencapaian pelajar. Sikap dan minat seseorang terhadap mata pelajaran geografi adalah berkait rapat yang perlu disokong oleh guru dan ibu bapa. Hal ini disebabkan, kedua-dua individu ini terlibat secara langsung dalam perkembangan pembelajaran kanak-kanak yang boleh mempengaruhi pencapaian pelajar. Oleh itu, sekiranya keempat-empat pemboleh ubah ini tidak memainkan peranan dalam menarik minat pelajar dalam pembelajaran geografi, maka berlaku peminggiran mata pelajaran geografi di pihak sekolah kesan pencapaian yang rendah pelajar geografi. Kebimbangan langsung adalah mata pelajaran ini terus diabaikan dan tidak mustahil pada jangka masa yang panjang mata pelajaran ini akan dimansuhkan sepenuhnya pada peringkat menengah atas. Justeru itu, pihak ibu bapa, sekolah, kerajaan dan guru perlu berganding bahu dalam meningkatkan pencapaian geografi pelajar serta menggalakkan pelajar untuk mengambil mata pelajaran ini.

\section{Rujukan}

Abd Razak, Z., \& Noraini, M. S. (2011). Konteks Keluarga Dan Hubungannya Dengan Penglibatan Ibu Bapa Dalam Pendidikan Anak-Anak Di Sekolah Menengah. (Family Context And Its Relationship With Parental Involvement In Their Children's Education In Secondary Schools). Jurnal Pendidikan Malaysia, 36(1), 35-44.

Abdul Hamid, A., Mohmadisa, H., Mohd Faris, D., \& Muhamad Suhaily, Y.C.N. (2006). Isu-isu Pendidikan Geografi di Malaysia. Tanjong Malim: Penerbit UPSI.

Abdul Said, A., Baharom, M., Mohd Yusof, A., Mohamad Johdi, S., \& Francis, N. (2011). Keberkesanan Penggunaan Model Bentuk Muka Bumi Sungai Bagi Meningkatkan Prestasi Pelajar Dalam Mata Pelajaran Geografi Tingkatan 1. National Seminar on History and Geography Education. Universiti Malaysia Sabah, Kota Kinabalu, 13 - 14 July.

Aishah, A.Z.A., Ruzaini,I., \& Siti Asiyah, A. (2011). Attitude (Part 1). http://eprints.utm.my/ 19940/1/001.pdf [16 Ogos 2015]

Alimi, O.S \& Balogun, B.N (2010). Teachers' Attributes As Correlates Of Students' Academic Performance In Geography In The Seconday Shcools in Ondo State, Nigeria. Pakistan Journal Of Social Science, 7(5), 388-392.

Aydın, F. (2011). Secondary School Students' Opinions About Course: A Qualitative Study. Archieves of Applied Science Research, 3(1), 297-305.

Azmy, M. (2012). Penglibatan ibu bapa penting. http://ww1.utusan.com.my/ utusan/Pendidikan/20120723/pe_01/Penglibatan-ibu-bapa penting\#ixzz42Nmey DMJ [8 Mac 2016]

Bronfenbrenner, U. (1979). The Ecological Of Human Development: Experiments By Nature And Design. Cambridge: Harvad University Press.

Cohen,L. Manion,L. \& Morrison,K. (2001). Research Method In Education (5 th.ed). London: Rautledge Falmer.

Farooq, M. S., Chaudhry, A. H., Shafiq, M., \& Berhanu, G. (2011). Factors Affecting Students' Quality Of Academic Performance: A Case Of Secondary School Level. Journal of Quality and Technology Management, VII(II), 1-14. 
Hibszer, A. (2011). Perceiving Geography As A School Subject By Pupils Of Lower Secondary School (In The Cities Of Silesian Voivodeship). Sonowiec: University of Silesia.

Johari, H., \& Norsuriani, A. A. (2011). Faktor-Faktor Yang Mempengaruhi Minat Terhadap Matematik Di Kalangan Pelajar Sekolah Menengah. http://eprints.utm.my/11972/1/Faktor.pdf [23 Oktober 2015]

Kanjiru, G. E. (2014). Factor Influencing Students' Kenya Certificate Secondary Education Performance In Geography Changamwe Distric, Mombasa County, Kenya. [Tesis Ijazah Sarjana]. University of Nairobi.

Kaya, H. (2011). Primary $6^{\text {th }}$ Grade Students' Attitudes Toward The Social Studies Lessons Aided with Geographic Information Systems (GIS): Karabuk Case. Middle-East Journal of Scientific Research, 7(3), 401-406.

Kementerian Pendidikan Malaysia. (2015). Pelajaran Menengah. http://www.moe. gov.my/my/pelajaran-menengah [18 Mei 2015]

Krejcie, R., \& Morgan, D. (1970). Determining Sample Size For Research Activities. Educational and Psychological Measurement, 30, 607-610.

Mastura, O. (2014). Kesan Penggunaan Google Earth Dalam Pembelajaran Peta Mata Pelajaran Geografi. [Tesis Ijazah Sarjana Pendidikan]. Universiti Pendidikan Sultan Idris.

Mohamad Johdi, S., Mazliza, K., \& Jane, F. H. (2012). Kajian Terhadap Faktor-Faktor Mempengaruhi Pencapaian Pelajar Dalam Penilaian Menengah Rendah Di Sabah. Labuan International Conference on Educational Research. Wilayah Persekutuan Labuan, 5-7.

Mohammad Abdillah, S., Asma, B., \& Zamri, A. (2015). Hubungan Antara Kecenderungan Minat Pelajar Dalam Bahasa Arab Dengan Kualiti Diri Guru Bahasa Arab MRSM Ulul Albab, Kota Putera. Journal of Human Capital Development, 8(2), 49-59.

Mohd Faris, D., Mohmadisa, H., \& Mohamad Suhaily Yusri, .C.N. (2013). Tinjaun Ke Atas Literasi Geografi Pelajar Institusi Pengajian Tinggi Awam di Semenanjung Malaysia. Dlm. Mohmadisa, H., Nasir, N., Mohamad Suhaily, Y.C.N \& Yazid, S. (Eds.), Pendidikan Geografi: Wadah Pendidikan Umum Untuk Masyarakat, 145-174. Tanjong Malim: Penerbit Jabatan Geografi dan Alam Sekitar Fakulti Sains Kemanusian, UPSI.

Mohmadisa, H., Nasir, N., Mohamad Suhaily Yusri,.C.N., \& Yazid, S. (2013). Pendidikan Geografi: Wadah Pendidikan Umum Untuk Masyarakat. Tanjong Malim; Penerbit Jabatan Geografi dan Alam Sekitar Fakulti Sains Kemanusian, UPSI

Mutua, K. R. (2012). Factor Influencing Performance In Geography In Kenya Certificate Of Secondary Eduaction In Nzaui Distric Makueni County. Nzaui: University Kenyatta.

Nihra Haruzuan, M. S., \& Chandrathevy, A. K. (2010). Hubungan Sikap (Komitmen, Emosi, Berwawasan) Dengan Pencapaian Akademik Pelajar PKPG (SPT, SPN, SPH) Tahun Akhir Di Fakulti Pendidikan, UTM Skudai. Skudai, Johor Bahru: Universiti Teknologi Malaysia.

Norhaida, S., Muhammad Firdaus, M. S., Nor Rosmawati, A. K., Farah, M. S., \& Haliyana, T. (2015). Mengkaji Hubungan Sokongan Ibubapa Terhadap Prestasi Akademik Pelajar Kolej Universiti Islam Antarabangsa Selangor (KUIS). Proceeding of the 2nd International Conference on Management and Muamalah, $472-483$.

Normah, D. (2012). Kesan Penggunaan Video Dan Buku Teks Terhadap Pencapaian, Minat Dan Motivasi Pelajar Dalam Topik Putaran Dan Peredaran Bumi. [Tesis Ijazah Sarjana Pendidikan] Universiti Pendidikan Sultan Idris.

Norzahida, M. (2013). Komitmen Ibu Bapa Menerusi PIBG Dalam Membantu Pencapaian Akademik Pelajar. [Tesis Ijazah Sarjana Muda]. Universiti Tun Husseien Onn Malaysia.

Nuratu, M. (2014). Some Issues On Gender And The Teaching Of Geography In Kano State Secondary Shcools. American Journal of Humanitties and Social Sciences, 2(2), 105-110

Ottati, D.F. (2015) Geographical Literacy, Attitudes, And Experiences Of Freshman Students: A Qualitative Study At Florida International University. FIU ElectroniC Theses and Disessertations Paper 1851.

Ozdemir, U. (2012). High School Students' Attitudes Towards Geography Courses (Karabuk Sampel-Turkey). World Applied Science Journal, 17(3), $340-346$.

Pallant, J. (2010). A step by step guide to data analysis using the SPSS Program (4th .ed.). Australia: Mc Graw-Hill.

Rilwani, M. L., Akahomen, D. O., \& Gbakeji, J. O. (2014). Secondary School Students' Attrition In Geography In Esan West Local Government Area, Edo State , Nigeria : The teachers' perspective. Sky Journal of Educational Research, 2(4), 28-36.

Rohani, A., Hazri, J., \& Nordin, A. R. (2010). Hubungan Guru-Pelajar Dan Kaitannya Dengan Komitmen Belajar Pelajar: Adakah Guru Berkualiti Menghasilkan Perbezaan Pembelajaran Antara Jantina Pelajar? Jurnal Pendidikan Malaysia, 35(2), 61-69.

Roslee, T., \& Mohamad Saifullah, M. S. (2013). Penggunaan Aplikasi Google Earth Dalam Meningkatkan Prestasi Pelajar Mata Pelajaran Geografi Di Sekolah Menengah. Seminar Pendidikan Sejarah Dan Geografi, 29-30.

Shamsiah, S., \& Azman, H. (2015). Kebolehan Guru-Guru Mata Pelajaran Geografi Menggunakan Teknologi Maklumat Dan Komunikasi (TMK) Dalam Pengajaran Dan Pembelajaran Di Sekolah Menengah Malaysia. Journal of Global Business and Social Entrepreneurship (GBSE), 1(2), 35-43.

Soon Singh, A.B.S., Roslee, T., \& Dg. Norizah, A.K. (2013). Dilema Menguasai Kemahiran Geografi Dalam Kalangan Pelajar Sekolah Menengah Luar Bandar di Sabah: Satu kajian kes di SMK Bongkol, Pitas. Sabah. Dlm Mohmadisa, H., Nasir, N., Mohamad Suhaily, Y.C.N \& Yazid, S. (Eds.), Pendidikan geografi: Wadah Pendidikan Umum Untuk Masyarakat, 29-42. Tanjong Malim: Penerbit Jabatan Geografi dan Alam Sekitar Fakulti Sains Kemanusian, UPSI.

Tomal, N. (2010). High School Students' Attitudes Toward Geography And The Questions They Wonder About. Scientific Research and Essays, 5(13), 1729-1733.

Uly, U. (2012). Pengaruh Minat Belajar Dan Motivasi Belajar Terhadap Prestasi Belajar Mata Pelajaran Matematika Siswa Kelas IV Dan V Pada Mi Riyadlotul Ulum Kunir Kecamatan Dempet Kabupaten Demak tahun ajaran 2011/2012. [Tesis Ijazah Sarjana Pendidikan] Sekolah Tinggi Agama Islam (STAIN).

Zahara, A., \& Suzela, B. (2011). Kesan Strategi Pembelajaran Koperatif Terhadap Pencapaian Geografi Tingkatan Satu - Topik Tumbuhan Semula Jadi Dan Hidupan Liar (The Impact Of Cooperative Learning Strategy On The Geography Achievement Of Form One : Topics Forest And The Wild Life). Jurnal Pendidikan Malaysia, 36(1), 1-10.

Zulkifli, A. H., Jamilah, O., Aminah, A., \& Ismi, A. I. (2011). Hubungan .Antara Penglibatan Ibubapa Dan Pencapaian Akademik Pelajar Miskin Di Negeri Selangor. Journal of Islamic and Arabic Education, 3(2), 31-40. 